\title{
Belphégor
}

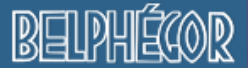

Littérature populaire et culture médiatique

18-2 | 2020

Roman Populaire Espagnol - Roman historique,

1900-1950

\section{“Quatre francs par semaine !": el dinero como motor y motivo en el folletín decimonónico}

Juan Frau

\section{(2) OpenEdition}

\section{Journals}

Edición electrónica

URL: http://journals.openedition.org/belphegor/2961

DOI: 10.4000/belphegor.2961

ISSN: 1499-7185

Editor

LPCM

Referencia electrónica

Juan Frau, " "Quatre francs par semaine !": el dinero como motor y motivo en el folletín

decimonónico », Belphégor [En ligne], 18-2 | 2020, mis en ligne le 11 décembre 2020, consulté le 28

avril 2021. URL : http://journals.openedition.org/belphegor/2961 ; DOI : https://doi.org/10.4000/

belphegor.2961

Este documento fue generado automáticamente el 28 abril 2021.

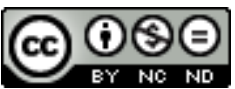

Belphégor est mis à disposition selon les termes de la Licence Creative Commons Attribution - Pas d'Utilisation Commerciale - Pas de Modification 4.0 International. 


\title{
"Quatre francs par semaine !": el dinero como motor y motivo en el folletín decimonónico
}

\author{
Juan Frau
}

1 La novela popular del siglo XIX, que en Francia y España adopta sobre todo el cauce y la forma de la entrega folletinesca, nace, como es sabido, de la conjunción de una serie de factores de carácter técnico, económico, social y cultural, entre los que destacan la creciente alfabetización y un notable desarrollo de la maquinaria de impresión, lo que establece las condiciones ideales para emplear los recursos literarios en la creación de un mercado de dimensiones hasta entonces impensables, todo ello con un gran protagonismo de la prensa periódica. La novela puede entonces llegar a casi cualquier hogar -al menos en el ámbito urbano-, y los editores conciben e impulsan un modelo literario que relega lo estético a un segundo plano y que centra sus esfuerzos en despertar la curiosidad de la mayoría de los lectores y asegurar su fidelidad a lo largo de la publicación seriada. En este concepto, el de la mayoría de los lectores o el gran público, radica la clave del folletín, y en él se manifiesta lo popular de esta literatura. Desde el punto de vista comercial, conviene no renunciar a ningún posible lector, de modo que será imprescindible ofrecer -ofertar- un producto atractivo, pero también accesible y sencillo. De ahí la gran importancia de aquellos elementos que atañen a los intereses y preocupaciones del average man, ese hombre corriente que, en una proporción significativa, es en realidad la mujer corriente, si hemos de creer a AnneMarie Thiesse ${ }^{1}$ o si vemos cómo Pérez Escrich, Nombela o incluso Altadill se dirigen a veces de modo explícito a sus lectoras.

2 Entre esos intereses y preocupaciones destacan los problemas derivados de las relaciones sociales, los vínculos familiares y los sentimientos amorosos -que en las ficciones tienden a confluir en el matrimonio- y, en general, aquellos relativos a la integración del individuo en la sociedad y su posición en ella. Este, de hecho, sería uno de los rasgos fundamentales para caracterizar a los personajes, y con frecuencia adquiere una importancia capital a la hora de urdir la trama narrativa y de plantear y 
resolver los conflictos: una de las fórmulas más recurrentes y exitosas para concluir la novela será el triunfo social del héroe. Por otra parte, entre los rasgos más innovadores, significativos y valorados del folletín estará precisamente su capacidad para recrear el amplio espectro de las clases sociales, lo que llega a ofrecer una imagen de cierta complejidad, e introduce en el ámbito literario algunos tipos sociales que habían estado tradicionalmente excluidos; novelas como las de Sue o Ayguals dan cabida al humilde obrero o incluso a los habitantes de la más olvidada marginalidad. Esta aspiración a recrear la arquitectura de la sociedad, aunque sea utilizando más la brocha que el pincel -como dice Nettement de Sue, o Galdós de Ponson du Terrail ${ }^{2}-$, se hace especialmente notoria en aquellos folletines que Ferreras denominaba de carácter dualista ${ }^{3}$. Ese dualismo tiene una clara dimensión ideológica, y según la orientación del autor -o del editor-, unos $\mathrm{u}$ otros estratos sociales encarnarán la virtud o la degradación: los obreros pueden representar la incultura y la brutalidad más primitiva o bien la honestidad y la solidaridad en su más alto grado, y, en una medida recíproca, la alta burguesía o la aristocracia -a veces en evidente decadencia- exhibe un poder siempre determinante en el curso de la ficción, ya sea para hostigar al obrero o amenazar la honra de la heroína, ya sea para acudir en su defensa.

\section{Escribir por dinero}

3 En este universo urbano, escenario de revueltas, crímenes y todo tipo de intrigas, el elemento que mayor presencia y peso tiene, desde cualquier punto de vista, suele ser el dinero, sustituto metonímico de la noción de poder. La posición que el personaje ocupa en la sociedad está casi siempre determinada por su capacidad económica -que no lo esté puede ser igualmente revelador-. Pero antes de analizar los aspectos puramente ficcionales, conviene recordar algunas consideraciones de los propios novelistas al respecto, y subrayar el vínculo indisoluble que estos mantienen con el dinero. El novelista por entregas es el máximo exponente de la industrialización de la cultura escrita: factura un producto para el consumo a cambio de un estatus laboral y una posición económica a los que nunca antes había tenido acceso, lo que implica una notable renuncia, la de la libertad estética. El nuevo escritor vende sus obras por líneas o páginas, y acata en todo momento las directrices de quien le paga, el editor, esforzándose por garantizar la rentabilidad de la publicación mediante recursos de todo tipo. El estilo, la estructura y los temas de sus novelas están condicionados por ese objetivo, y ahí tendrá su origen la pobre consideración del género, desde el célebre ataque de Sainte-Beuve hasta la posterior tendencia a definirlo con términos como paraliteratura o subliteratura.

4 Alexandre Dumas ejemplifica a la perfección la abrumadora presencia del dinero en la vida del folletinista, con sus inmensas ganancias, la contratación de Maquet y otros colaboradores, la dilapidación de la fortuna o las argucias para extraer el mayor rendimiento posible del trabajo. Es muy reveladora la anécdota que cuenta Hippolyte de Villemessant, fundador de Le Figaro, sobre su reacción al saber que los directores de La Presse y Le Siècle habían acordado pagar menos por cada línea demasiado corta: Dumas tachó de repente una página y dijo haber matado a Grimaud ${ }^{4}$, el taciturno criado de Athos que apenas contestaba con monosílabos, y a quien había forjado así para producir más páginas con menos texto. La amenaza, como el lector sabe, no llegó a 
cumplirse, pero la escena ilustra cómo lo económico, factor a priori extraliterario, puede condicionar la escritura de la obra.

5 Julio Nombela alude de continuo en sus memorias a las cantidades que cobraba por sus relatos y otros menesteres literarios. Detalla cómo la editorial parisina Rosa y Bouret le ofreció 300 francos por novela, cómo los editores Manini le pagaban cinco duros por cada entrega de ocho páginas, y Manero, de Barcelona, le daba seis; cuenta también cómo probó con éxito la técnica de dictar a un taquígrafo, lo que le permitió ganar hasta 18 duros diarios y, en fin, presume de que entre 1865 y 1872 su escritura llegó a producirle cerca de 20.000 pesetas al año ${ }^{5}$. También cuenta lo que ganaban otros folletinistas como Fernández y González o Pérez Escrich, e incluso lo que pagaban los suscriptores. La presencia del dinero en las memorias de Nombela es muy notable; el autor destaca la importancia de la estabilidad económica y se muestra orgulloso de lograrla gracias al nuevo mecenas, que ya no es un aristócrata o un potentado, sino el conjunto de los lectores comunes.

\section{Dinero y poder}

6 En cuanto a la importancia que adquiere el dinero como motivo literario e incluso como motor de las ficciones, es de mayor interés un breve pasaje de estas memorias en el que Julio Nombela refiere cómo en el verano de 1847, todavía lector en ciernes, El conde de Montecristo lo absorbió hasta alterar su rutina y causarle una incontrolable fiebre, primero metafórica y luego física. Dentro de esa evocación, leemos: “Adquirí la noción de la riqueza como medio eficaz de dispensar el bien y castigar el mal, deseé ser un nuevo Dantés, aun a costa de las persecuciones y martirios de que fue víctima" ${ }^{6}$. Es decir, el niño que entonces era Nombela repara en que Dantès sólo puede convertirse en Montecristo, acometer sus fabulosos planes y ejercer como un verdadero agente de la Providencia, gracias al respaldo de un tesoro no menos fabuloso. El dinero equivale a la fuerza o al poder, y la capacidad de acción de un héroe de novela, como su posición social, depende en gran medida de sus recursos económicos. En efecto, Edmond Dantès, modesto aunque prometedor oficial de la marina mercante, llegará a ser un respetable y admirado conde, tan misterioso y seductor como rico, y alternará con la alta sociedad parisina. Además, será el dinero -junto a la astucia- lo que le permita llevar a cabo sus complejos planes de venganza, como cuando con 25.000 francos soborna al telegrafista para difundir un bulo y causar la pérdida de un millón a su enemigo, Danglars. Parte de su atractivo social consiste en esa impasibilidad con la que se permite cualquier gasto o capricho, por lujoso que sea.

7 Aunque también hay protagonistas de clase media o de extracción humilde, un rasgo particular de cierto tipo de héroe folletinesco es precisamente la posesión de una riqueza, al menos en apariencia, ilimitada, lo que le capacita para realizar casi cualquier empresa imaginable. Igual que Dantès dispone del tesoro de Montecristo, Nemo, el capitán del Nautilus, tiene acceso a todo el oro americano de los fondos marinos, y Joseph Balsamo parece poseer el conocimiento de la piedra filosofal, lo que causa estupefacción y le presta un halo de grandeza. En un género que de continuo persigue causar una honda impresión en el lector, la inmensidad de las riquezas, tenga o no influencia en el curso de los acontecimientos, es siempre un factor sobresaliente. La incalculable fortuna del indio Miantucatuc, en Historia de un hombre contada por su esqueleto, hace que este sea digno de admiración. Y de envidia; su esposa, la pérfida 
Adelaida, habla así de sus tesoros: “-jInmensos! ¡Como no los tiene ningún soberano en Europa! ¡Perlas... montones de perlas...; quien posea estos tesoros puede tener palacios..., trenes... ¡Admirables trenes!... ¡Puede brillar como brillan los que pueden hacer de sus manos dos ríos de oro!" ' . De manera paradójica, la posesión de esa fortuna será la causa de su muerte a manos de Adelaida, impaciente por heredarla.

No siempre la riqueza es tan notoria e impresionante como en estos casos, pero la adecuada progresión de la trama sería imposible si los protagonistas no dispusieran de dos recursos fundamentales: tiempo libre y dinero -"el tiempo es dinero", certifica un personaje de Ceferino Tresserra-. Las grandes hazañas suelen ser incompatibles con las exigencias de un empleo convencional -salvo excepciones: Rouletabille es corresponsal en Rusia o Bulgaria-. Aunque de manera más discreta que los héroes antes citados, Rodolphe de Gerolstein, prototipo de todos ellos, acomete su tarea filantrópica desde la posición de un príncipe, y Phileas Fogg emprende su vuelta al mundo con una manifiesta indiferencia ante los gastos necesarios -sin mencionar la cuantiosa apuesta inicial-. Quevedo, convertido en personaje de folletín por Fernández y González, subraya lo obvio cuando afirma que "dineros son poder", al recibir del conde-duque de Olivares 500 doblones de oro; luego añade: "poderoso caballero es don Dinero; que quien tiene dinero, lo tiene todo, y a tal puede llegar de rico que le hagan emperador del mundo"; y otros personajes folletinescos afirman que "el dinero hace milagros" 10 , o que "cuando se tiene dinero en abundancia, se posee una varita mágica que hace milagros". ${ }^{11}$

9 Ahora bien, Nombela, pese a ser consciente de su poder, no deja de mostrar claras reservas sobre el dinero. En Mendigos y ladrones sólo un personaje cínico -Ascanioafirma, ofendiendo la sensibilidad del honrado protagonista: "El dinero es siempre un señor feudal con todos sus derechos, y ganar mucho dinero sin trabajar es el bello ideal de todos los romanos"12. El resto de referencias en esta novela al dinero son muy negativas; otro personaje subraya su influencia perniciosa: "El dinero brilla tanto, que ofusca las miradas de todos"13, y el narrador sentencia que "el dinero es casi siempre el mayor enemigo de los buenos sentimientos"14. En La piedra filosofal se habla precisamente de una mujer a la que "el goce del dinero aniquiló en su alma los sentimientos maternales" ${ }^{15}$, y no deja de ser significativo que Nombela publique en $1875 \mathrm{El}$ vil metal, y que emplee esa misma expresión en El bello ideal del matrimonio, La mujer de los siete maridos, Pepe-Hillo o La niña de oro. El juicio sobre el dinero, pues, es a menudo ambiguo; como afirma Àngels Santa, sus raíces están a veces en el robo y la explotación y da prestigio a gente que no lo merece, pero también permite al héroe hacer el bien ${ }^{16}$, y a su facultad para deslumbrar a personajes y lectores suele unirse la consideración de un elemento impuro y nocivo.

\section{La riqueza como objetivo o como recompensa final}

Lo que para unos personajes es el punto de partida, para otros es el objetivo. Abundan las novelas populares en las que el motor principal de la trama es una gran cantidad de dinero que puede cambiar de manos. Sucede de una forma codificada e intrínseca al modelo en la novela criminal y policíaca. Aunque algunos criminales formidables, como Fantômas o Fu-Manchu, se mueven por otros intereses, incluso por pura maldad, en los inicios del subgénero el móvil elemental -salvo en los crímenes pasionales- es el dinero. Los múltiples y variados crímenes de Rocambole y el Club des Valets-de-coeur o de 
Bozzo-Corona y la sociedad de Les Habits Noirs, en las novelas de Ponson du Terrail y Paul Féval, tienen su origen en la voluntad de hacerse con el dinero ajeno. A menudo el conflicto de la novela surge de una suplantación ilegítima de la personalidad, que persigue los bienes del suplantado o el acceso a una herencia considerable. Le Juif errant, de Sue, se estructura en torno a las intrigas del ambicioso Rodin para apropiarse de la exorbitante cifra que deberían heredar los Rennepont, unos 212.000.000 de francos. La ambición de riquezas suele estar en el núcleo argumental de la novela policíaca. Émile Gaboriau, precursor del roman judiciaire en Francia, plantea Le Dossier $n^{\circ} 113$ a partir del robo de 350.000 francos de una caja fuerte, lo que da lugar a la investigación del inspector Lecoq, que desvelará una larga historia de traiciones y chantajes. Con el tiempo, el subgénero se diversifica e incluso se subvierte, de modo que el lector simpatiza con quien busca el dinero al margen de la ley. Si la identificación con Rocambole se hacía en ocasiones difícil, por su excesiva crueldad y falta de escrúpulos, personajes como Arsène Lupin -al igual que antes Raffles-, obtendrán una consideración mucho más positiva y amable.

11 Hay otros modelos de novela que toman como tema o motivo destacado la búsqueda o el descubrimiento de una gran fortuna. Dos relatos de aventuras que pueden considerarse arquetípicos al respecto de esta mitología de la riqueza serían King Solomon's Mines, de H. R. Haggard, y Treasure Island, de R. L. Stevenson; los emplazamientos lejanos o exóticos suelen ser propicios para acumular grandes riquezas, como también sucede en L'Étoile du sud, de Jules Verne. En el folletín hispánico de la época, tendente al realismo y con un sentido costumbrista e histórico, se prefiere novelar las únicas formas, improbables pero factibles, en las que un ciudadano humilde podía hacerse rico. Una de ellas conserva algo del espíritu aventurero y se presta a cierto exotismo: embarcarse para las colonias americanas. Al menos dos de las novelas de Nombela se basan en esta opción: La fiebre de riquezas. Siete años en California, descubrimiento del oro y explotación de sus inmensos filones, y Los indianos. Véase lo que afirma un personaje de esta última: "Es el único modo de hacer fortuna (...). No hay una casa buena en todo el valle de Baztan que no albergue un indiano (...); pueden darse por bien empleados los trabajos que se pasan en el otro mundo con tal de volver rico a su aldea" ${ }^{17}$. El indiano, familiar en la literatura hispánica desde el siglo XVII, representa el éxito económico y la posibilidad de un cambio de clase social que no siempre se acepta de buen grado. A veces se considera un premio merecido a una decisión valiente y un esfuerzo prolongado, y otras, dentro de la añoranza de la vieja aristocracia, como la incómoda elevación de un advenedizo. Será la novela realista de Galdós, Clarín o Pereda la que profundice en esas diversas percepciones de la integración del indiano en la sociedad peninsular, pero autores como Nombela o Fernández y González ya conceden cierto protagonismo a un tipo que era muy reconocible, sobre todo en zonas costeras y propensas a la emigración. Todavía a finales del siglo XIX Gustavo Morales publica $\mathrm{El}$ indiano de Valdella; luego, en los primeros años del XX, El noticiero bilbaíno incluirá en su folletín la novela India e indiano o las aventuras de un joven vasco en América, de Enrique Ortiz de Zárate, y Leopoldo López de Saa publica Los indianos vuelven.

12 La otra forma improbable de hacer fortuna y cambiar de estrato social reside en el puro azar de la lotería -“l'opium de la misère", según Balzac en Les Célibataires- o el juego y las apuestas, aunque en el universo moralizante del folletín es más frecuente arruinarse que enriquecerse por este medio. Eugenio García Ruiz, que llegaría a ser ministro de Gobernación, publica por entregas en 1851 Don Perrondo y Masalegre, que dedica un 
capítulo a la lotería: mientras una castañera y un campesino gallego celebran con tosco alborozo su premio de 3.000 duros, entre las bromas de unos y la envidia de los más, el protagonista, Masalegre, introduce la nota ejemplar: "Si ustedes quieren lograr la fortuna, que en vano aguardan de la lotería, jueguen de la manera juiciosa y prudente que yo he jugado" ${ }^{18}$, los ingresos regulares en la caja de ahorros que, tras veinte años, a él le permiten retirar 26.000 reales. En otra novela de la época, Historia de un bribón dichoso, son varios los personajes que fían su suerte a "aquel engañoso cebo de la codicia, recurso de los desesperados y norte de los holgazanes" ${ }^{19}$; entre los desesperados está Juliana, esclava cubana que juega a la lotería para comprar su libertad, y entre los codiciosos don Eustaquio, que la engaña cambiando un billete premiado con 2.500 duros por otro sin premio. Don Eustaquio acabará la novela en una situación económica inmejorable, pero odiado y despreciado por todo el mundo. El dinero de la lotería rara vez da la felicidad en el folletín. Otro caso significativo es el de Los 300.000 duros: historia de un pobre hombre, de Nombela, donde don Cosme gana el premio gordo de nochebuena pero, pese a sus buenas intenciones, terminará casi en la ruina tras fundar un periódico, invertir mal en la bolsa, y ser víctima de todo tipo de decepciones y engaños. Bolsa y lotería también se asocian en Barcelona y sus misterios, de Altadill, donde el narrador, al hilo de su crítica social, denuncia la ficción dolosa de las finanzas: "Se dice que la Bolsa es un juego. Nosotros creemos que es, más que juego, fullería (...). En el juego (...) el azar decide; en la Bolsa no decide el azar. El que talla, ha visto antes las cartas (...). He aquí por qué siempre gana el banquero"20.

\section{Pobreza y riqueza en el folletín: el dualismo social}

Otra parte importante de la producción folletinesca que concede gran protagonismo a los aspectos económicos sería la tendencia del dualismo social, que introduce una visión crítica desde una óptica reformista cercana al socialismo utópico. En esa línea sobresalen Eugène Sue y su émulo español, Wenceslao Ayguals de Izco; su preocupación ante las cuestiones económicas es, cuando no explícita, evidente, tanto por los grandes números de la política monetaria como en los matices, más humanos, de la economía doméstica.

Si el narrador decimonónico, en general, tiende a un excesivo intervencionismo, en el folletín de las primeras décadas abundan las extensas digresiones que sirven de cauce para expresar opiniones de toda índole, tanto metafictivas como referidas al ámbito de la moral o la política. En el caso de Sue o de Ayguals, ya sea en el cuerpo de la narración o en profusas anotaciones al pie, muchos de esos excursos conforman, en su conjunto, una suerte de programa político que conjuga críticas acerbas y propuestas reformistas. Algunas de esas intervenciones se centran en los aspectos económicos. Ayguals critica en María, la hija de un jornalero la política gubernamental de impuestos, el funcionamiento de la bolsa o los dispendios injustificados de la administración pública. En el capítulo IX, por ejemplo, opina sobre cómo debe repartirse la riqueza en la sociedad y luego censura las excesivas partidas destinadas al ejército y a exministros, generales y altos funcionarios "cuyas funciones se reducen a chupar cual sanguijuelas el jugo de la nación" ${ }^{21}$ y detalla en qué se invierte "la exorbitante suma de mil ciento ochenta y cuatro millones trescientos setenta y siete mil ciento setenta y tres reales"; el listado es minucioso y ofrece la cantidad exacta destinada al palacio real, a los cuerpos colegisladores, al ministerio de Estado, a Justicia, Marina, Gobernación, Hacienda, 
Iglesia y ministerio de la Guerra. Vuelve a cargar, después, contra aquellas "personas adictas" ${ }^{22}$ a las que también se favorece, y subraya el contraste con los trabajadores honrados y humildes que sobreviven como pueden. Ayguals insiste en oponer el "ciudadano virtuoso" al "corrompido palaciego", verdadero leitmotiv de la obra, y vuelve a ilustrar ese injusto contraste mediante el desglose de gastos asociados al monasterio de El Escorial; la conclusión es predecible: “¡Cuán costosos han sido siempre los reyes al pobre pueblo! ¡Qué contraste entre la grandeza de holgazanes palaciegos y el hambre de los artesanos condenados a un trabajo continuo y penoso!"23.

Estas grandes cifras se complementan con la consignación de las pequeñas cantidades que integran el salario de los menos favorecidos. La novela por entregas gusta de la confrontación de los extremos; frente a las abrumadoras cifras de las fortunas enormes y los grandes dispendios, llama la atención la modestia de lo que ingresan los obreros o las familias humildes. Muy al principio del relato, Ayguals ya ha informado sobre lo que ganaban los padres de María: catorce reales Anselmo como albañil y cinco Luisa como costurera. Pero es un breve período de bonanza que dará paso a una situación insostenible. Más tarde sabremos que el hermano mayor de María gana cuatro reales diarios como cajista. Ayguals no hace sino compartir la preocupación de su admirado Sue por las condiciones económicas de los trabajadores. Más allá del trasfondo de la fabulosa herencia, en Le Juif errant destaca el interés por las condiciones laborales y económicas de las clases bajas. Sus páginas glosan las bondades del Sr. Hardy, empresario ideal, o bien exponen la forma más justa y conveniente de organizar los negocios y distribuir los beneficios, pero uno de los momentos más enfáticos tiene lugar al presentar a un importante personaje, la Mayeux.

Contrahecha, sensible y bondadosa, la Mayeux reúne además todas las virtudes del trabajador honesto. La exposición de sus condiciones de vida se convierte en un alegato, y el caso particular va adquiriendo un valor simbólico, representativo de todo un colectivo de oprimidos por la injusticia social; la Mayeux ilustra los errores y desajustes de una sociedad mal diseñada. Desde el punto de vista retórico, en este capítulo se repite periódicamente el sintagma "quatre francs par semaine", que va cargándose de nuevos matices y creciendo en intensidad. Hermana pobre de la celebrada reina Bacanal, se nos dice que "elle la regretta toujours et continua à travailler assidûment, gagnant à grand-peine quatre francs par semaine" ${ }^{24}$, y que debe afrontar una jornada de doce o quince horas "qui lui donnait en moyenne un salaire de quatre francs par semaine!”. Después llega otra exclamación de texto sobrio y objetivo que se apoya en la tipografía para apelar a los lectores: "La Mayeux vivait donc avec QUATRE FRANCS PAR SEMAINE..." ${ }^{25}$. El narrador insiste; pese a lo sorprendente, el hecho está documentado: "nous allons constater de quelle façon une pauvre jeune fille peut exister avec quatre francs par semaine"; y detalla cómo se administran esos cuatro francos para cubrir los gastos imprescindibles: 84 céntimos para tres kilos de pan de segunda calidad, 20 céntimos de agua, 50 de grasa o sebo, 7 de sal, 40 de carbón, 33 en velas, 25 para hilo y agujas, etc. En nota editorial al pie, Sue certifica lo verosímil de estas cuentas de acuerdo con las estadísticas existentes. El resto del capítulo subraya las privaciones anejas a una situación tan insostenible. Todavía una vez más, antes de referir otros aspectos del personaje, se hará explícito su carácter simbólico y prototípico: "Le type que nous allons tâcher de développer dans la Mayeux résume la condition morale et matérielle de milliers de créatures humaines, obligées de vivre à Paris avec 4 francs par semaine" ${ }^{26}$. La cifra de cuatro francos por semana se repite en otras partes de la obra, siempre con claras connotaciones: deviene símbolo de la pura 
subsistencia. Es lo que Rose y Blanche saben que podrían ganar cosiendo, y la cantidad que conmueve a Florine, por lo que tiene de miserable. Céphyse, la reina Bacanal, dice preferir la vida indolente que alterna momentos de opulencia y precariedad a un trabajo seguro que le proporcionaría cuatro francos a la semana, y así se convierte para Sue en la imagen del ángel caído; confiesa que si pudiera ganar quarante sous diarios doce francos semanales- aceptaría gustosa la vida trabajadora, pero no lo hará por una miseria. Sue está dando a entender, una vez más, que la dignidad laboral es el medio más seguro de garantizar una vida sana y ordenada, para el individuo y para la sociedad.

17 La mención de pequeños salarios o de considerables fortunas, en este tipo de folletines, cumple varias funciones: sirve a la vez para caracterizar a los personajes y para darle al mundo de ficción una mayor densidad, para representar con mayor realismo el modelo social que el novelista examina, ese modelo dualista en el que, tal como se formula en $\mathrm{El}$ cura de aldea, "el dinero es la línea que separa a la humanidad que ríe, de la humanidad que llora" ${ }^{27}$.

\section{Una contabilidad escrupulosa}

18 Es especialmente significativa la presencia continua en el folletín de referencias y alusiones menores al dinero, ajenas al plan general de la obra y de apariencia gratuita o casual. En ellas se revela con claridad la ideología subyacente en la obra y, en gran medida, en el género. Un repaso no demasiado exhaustivo de algunas obras de los folletinistas españoles de éxito revela de inmediato que el dinero es una presencia constante, con numerosas menciones de un extraordinario detallismo, sobre todo cuando el foco se centra en personajes de las clases más bajas o que se encuentran en una difícil situación económica.

19 El frac azul, de Enrique Pérez Escrich, nos servirá para observar esta práctica de la anotación minuciosa. El relato narra las dificultades que atraviesa un escritor de literatura popular -Elías- hasta alcanzar el éxito. Ya al principio se describe al poeta de provincias como alguien que llega a Madrid con 200 reales en el bolsillo, algo que se cumple en los casos de Arturo -narratario del grueso de la novela-, y Elías -trasunto de Pérez Escrich-. A partir de ahí, las referencias concretas al dinero no cesan; Elías cobra 320 reales por su primera comedia, pide a su tío 100 duros -que acabarán siendo 50 (tres onzas de oro y una moneda de 40 reales)-, y al llegar a Madrid sabemos que "poseía por único capital dos pesetas en un rincón del bolsillo de su chaleco", ocho reales que "le aseguraban la existencia por dos días" ${ }^{28}$. Rechaza por motivos políticos una plaza en la redacción de El Clarín con un salario de 10.000 reales; un librero impresor le paga 19 reales por cada romance y un napoleón por cada pliego de aleluyas -escribirá 30 romances y 12 aleluyas por 42 napoleones-; negocia con un editor la venta de una pieza dramática por mil reales que no cobrará, pero elabora una tabla para invertirlos: 240 reales para el alquiler, 120 para enseres de cocina, 140 para una silla y una mesa de despacho y 120 más para doce sillas usadas, dejando 380 para gastos inmediatos. Es un tipo de tabla habitual en la novela popular decimonónica; hemos visto la que detalla los gastos de la Mayeux, y en otras obras de Pérez Escrich hay otras similares: La mujer adúltera, e.g., incluye la factura inflada que un taimado posadero presenta a Fernando, calculando "con la frialdad de la avaricia, no lo que el huésped había gastado durante su permanencia en el mesón, sino lo que el señor marqués debía 
pagar" 29: "cena 110 reales, cama 40, piensos y limpieza del caballo 40, luz y asistencia del señor marqués 10; total 200 reales".

Volviendo a $\mathrm{El}$ frac azul, Elías gasta 70 reales al alquilar un coche de caballos por un imprevisto, lo que reduce su capital a la cuarta parte; ante sus apuros, el escritor Ventura de la Vega le entrega un billete de banco de mil reales, dando origen a una extensa reflexión del narrador que comienza: "Mil reales son una fortuna inmensa cuando caen en un bolsillo que no posee un cuarto. Cincuenta duros hacen crecer al pobre desheredado cincuenta líneas. El hombre que recorre las calles de una capital sin una peseta en el bolsillo, camina agobiado bajo el peso de su pobreza" ${ }^{30}$. Con el donativo, Elías alquila una buhardilla por cinco duros al mes, lo que motiva otro excurso contra vicios como la inflación y la especulación, que habría doblado el precio de los alquileres sin motivo: "subamos los alquileres un ciento por ciento; el que pagaba cinco duros que pague diez (...); el que no tenga, que duerma bajo el puente de Toledo" ${ }^{31}$. Tras la mudanza, Elías conserva un capital de 20 duros, con el que "tenía cubierto el presupuesto de un mes" ${ }^{32}$. Después, escribe tres artículos sobre la arquitectura grecorromana por 24 duros, a 160 reales cada uno, y más tarde compondrá para un sacerdote un memorial en forma de oda, por el que recibirá "diez monedas de a cinco duros" ${ }^{33}$. Tendrá que pagar cien reales para evitar la cárcel, tras jugar en un salón clandestino -y perder un duro-. Trabajará como corrector de imprenta por diez reales en jornadas de once horas; es muy poco, "pero diez reales, cuando no se tiene nada, hacen el efecto de una fortuna" ${ }^{34}$. Venderá los derechos de un drama por 600 reales con gran lucro para el empresario-, pero sólo un sobre anónimo con 2.000 reales le salvará del desahucio. Con esa donación renueva su vestuario y se deshace del frac azul que da título a la obra; entonces cambia su fortuna y al final de la temporada de comedias puede alquilar una casa que renta 6.000 reales al año, certificando su lugar de privilegio en el mundo de las letras.

Hemos revisado por extenso esta obra para que pueda apreciarse en su justa dimensión esa preferencia por el detalle en los aspectos económicos. No es, sin embargo, un caso aislado, sino un comportamiento recurrente, al menos en la llamada novela de costumbres contemporáneas. Por los folletines sabremos que en la segunda mitad del siglo XIX el pescado del día podía costar catorce reales y medio, una ración de caldo dos reales, un traje usado tres napoleones, un sombrero media peseta, un caballo 150 duros -diez veces más si es árabe-, el arreglo de unos zapatos 30 cuartos, y alquilar un coche durante una hora, dos pesetas. Se diría que en el mundo del folletín todo está tasado, y que hay una conciencia perenne de lo que se tiene y lo que se gasta, de lo que se necesita para vivir o para sobrevivir. Ni el escritor decimonónico ni sus lectores olvidan nunca que todo tiene un precio, y que todo gasto tiene su importancia.

\section{Dinero, apariencia y dignidad}

Cuando lo posee en grandes cantidades, el dinero hace a un personaje más atractivo y respetable ante los demás: la belleza o la virtud brillan más, y el vicio o los aspectos desagradables se desdibujan. En Historia de un hombre..., se nos dice que Clara, a pesar de su edad, "era una mujer adorable por su hermosura (...), ayudada por su talento y por sus inmensas riquezas" ${ }^{35}$. En efecto, se sirve de su fortuna para causar una impresión indeleble, y, sabedora de la importancia de las apariencias y de ciertas ceremonias sociales, gasta un millón de reales en una sola noche para organizar un baile; el mismo 
narrador parece participar del asombro ante el dispendio y da las claves de su significado: "quien para una sola noche gasta un millón... lo tiene de sobra, y quien tiene de sobra un millón..." ${ }^{36}$.

Otro personaje, esta vez de Historia de un bribón dichoso, le dice a don Cosme: "Indudablemente, vales hoy dos mil duros más que antes, suponiendo que algo valieses. En los tiempos que corren, el hombre no es más que una adherencia de su bolsillo" ${ }^{37}$, enunciado que refleja a la perfección la mentalidad imperante en la sociedad más superficial y materialista del universo folletinesco. Es la misma opinión que expresa el padre de Fernando en su lecho de muerte: "si bien es cierto que nunca te has ocupado en nada y que no has seguido ninguna carrera, tienes en cambio dinero, que es como tenerlo todo. Los pobres estudian y trabajan para los ricos" 38 ; o la que defiende el tío de Elías: "El hombre vale lo que tiene lo mismo aquí que en Pekín" ${ }^{39}$, visión contraria a la que defiende el propio Elías, que responde que un hombre de genio, un poeta o un filósofo, valdrá siempre mucho más que un rico sin más atributo que su fortuna. Es la lucha entre dos posturas irreconciliables, la que encarnaba la Mayeux, que valora la dignidad humana por encima de la materialidad de las posesiones, y aquella otra, más cínica, o más fiel al espíritu de los tiempos, que en la ficción dualista suele imponerse con notables excepciones- entre empresarios, aristócratas, políticos y, en las obras anticlericales, curas y frailes. El dinero de una persona establece su valor y su poder; otra máxima, esta del narrador de El frac azul: "El que tiene dinero puede decirse que posee el misterioso elixir para curarlo todo" ${ }^{40}$. Lo cierto es que el dinero allana las dificultades y domina a quien lo necesita o lo ambiciona. Con dinero, en Historia de un hombre... se soborna a los criados o se compra un veneno en el mercado negro. Es recurrente, además, el motivo de la dolorosa venta de un objeto apreciado, que pasa a manos de quien puede comprarlo: en La mujer adúltera, Carlos debe vender el retrato de Magdalena; en María, la protagonista vende su canario para ayudar a sus padres; en $E l$ frac azul, Enrica, enferma, ha de devolver el piano alquilado; en El poder negro, de Tresserra, María descubre su cabeza rapada, tras vender su cabello por 16 reales.

No es menos cierto que la dignidad de muchos personajes, sobre todo femeninos, reside en no ceder ante la seducción del dinero. El dinero tiene una dimensión ética, y también tiene pasado. Por una parte, quienes llevan a gala su honradez, y especialmente dentro de la pobreza, rechazan todo aquel dinero de procedencia dudosa o que pueda suponer una obligación en el futuro. Así se queja un personaje de La perdición de la mujer: "pero ese dinero quema mis manos, ofende mis canas, porque es el dinero del vicio, de la prostitución, y un hombre honrado no debe admitirlo" ${ }^{41}$. Es verdad que el dualismo también se muestra aquí, y hay quien carece de escrúpulos y sostiene que "una onza de oro, como esta sea de ley y tenga el peso marcado por el contraste, ¿quién diablos va a averiguar si ha pertenecido antes al verdugo?" ${ }^{42}$. La sociedad, en todo caso, se rige por el dinero. La desigualdad de la posición económica puede convertirse en un obstáculo para cualquier relación, sobre todo amorosa. En Historia de un hombre..., Sandoval, pretendiente de Clara, afirma que esta tiene un "defecto terrible", que es inmensamente rica, al contrario que él; el matrimonio sería difícil aunque al menos posible en la circunstancia inversa, pero los códigos de la época son un obstáculo insuperable. Es cierto que el dinero no puede comprarlo todo, pero con frecuencia se presupone que sí. "El dinero es la llave de oro que abre todos los corazones: ese también se abrirá", dice alguien que lo tiene, el conde Amadeo Polviani, pero el narrador nos aclara que no siempre tenía éxito. ${ }^{43} \mathrm{Y}$ un vizconde se queja, 
ofendido, porque sus doce millones de reales no le permiten adquirir un palco en el Teatro Real, al estar todos asignados ${ }^{44}$.

Hay toda una casuística en torno a las relaciones entre dinero y dignidad. Si son innumerables los ricos que deben su fortuna a la avaricia, la explotación o el engaño, también abundan en el folletín los filántropos que actúan como deus ex máchina y ponen su riqueza a disposición del débil cuando ya no parece haber ninguna salida. En todo caso, la novela popular refleja un mundo burgués y de valores burgueses, y no puede separar el honor del patrimonio. Los reveses económicos, las deudas contraídas o las pérdidas en el juego pueden conllevar la destrucción de la persona o la familia. Una de las mayores losas sobre cualquier personaje es una deuda que no puede satisfacer.

El dinero, en fin, llega a adquirir una importancia estructural en la ficción narrativa: puede ser la causa principal que guía las acciones de los personajes o bien el recurso imprescindible que las hace posibles, o convertirse en el centro de una serie de reivindicaciones y denuncias sociales, pero también es un elemento temático que aparece de forma recurrente, en un continuo segundo plano, para dar con fidelidad la más exacta imagen de su tiempo.

\section{NOTAS}

1. Anne-Marie Thiesse, Le roman du quotidien. Lecteurs et lectures populaires à la Belle Époque, Paris, Seuil, 2000, pp. 15-16.

2. Alfred Nettement, Études critiques sur le feuilleton roman, París, Lagny Frères, 1845, p. 72. Benito Pérez Galdós, Ensayos de Crítica literaria, Barcelona, Península, 1990, p. 219.

3. Juan Ignacio Ferreras, La novela por entregas: 1840-1900, Madrid, Taurus, 1972.

4. Les annales politiques et littéraires: revue populaire (16-9-1894).

5. Julio Nombela, Impresiones y recuerdos, Madrid, La última moda, III, 1910, pp. 141, 322, 325, 327.

6. Julio Nombela, Impresiones y recuerdos, Madrid, La última moda, I, 1909, p. 91.

7. Manuel Fernández y González, Historia de un hombre contada por su esqueleto, Biblioteca de la cultura andaluza. Sevilla, 1985, p. 163.

8. Ceferino Tresserra, La judía errante, Barcelona, Manero, 1862, p. 191.

9. Manuel Fernández y González, Amores y estocadas, Pamplona, Universidad de Navarra, 2002, p. 61.

10. Manuel Fernández y González, Los desheredados, Madrid, Manini, 1865, p. 71.

11. Enrique Pérez Escrich, La perdición de la mujer, Madrid, Guijarro, 1866, p. 617.

12. Julio Nombela, Mendigos y ladrones, Madrid, Manini, 1870, II. p. 135.

13. p. 360 .

14. p. 305.

15. Julio Nombela, La piedra filosofal, Madrid, La última moda, 1895, p. 36.

16. Àngels Santa, La literatura popular francesa: folletines y melodramas, Pagès/Universidad de Lleida, 2012, p. 30.

17. Julio Nombela, Los indianos. Misterios de la vida de los que van a América a hacer fortuna, Madrid, Querol y García, 1873, p. 12.

18. Eugenio García Ruiz, Don Perrondo y Masalegre, Avrial, Madrid, III, 1855, p. 351. 
19. Ramón Piña, Historia de un bribón dichoso, Madrid, Tello, 1860, p. 75.

20. Antonio Altadill, Barcelona y sus misterios, Barcelona, Torrens, [s.a.], p. 318.

21. Wenceslao Ayguals de Izco, María, la hija de un jornalero, Madrid, Imp. de Ayguals, 1847, p. 93.

22. p. 94.

23. pp. 206-207.

24. Eugène Sue, Le Juif errant, Paris, Paulin, 1845, p. 210.

25. p. 211.

26. p. 213.

27. Enrique Pérez Escrich, El cura de aldea, París, Garnier, 1870, p. 12.

28. Enrique Pérez Escrich, El frac azul, Madrid, Manini, 1864, p. 61.

29. Enrique Pérez Escrich, La mujer adúltera, II, París, Garnier, 1893, pp. 61-62.

30. El frac azul, cit., p. 210.

31. p. 212.

32. p. 213.

33. p. 229.

34. p. 298.

35. Op. cit., p. 41.

36. p. 45.

37. Op. cit., p. 107.

38. La mujer adúltera, cit., p. 35.

39. El frac azul, cit., p. 40.

40. p. 210.

41. La perdición de la mujer, cit., p. 731.

42. La mujer adúltera, cit., p. 34

43. La perdición de la mujer, cit., p. 204.

44. La mujer adúltera, cit., p. 229.

\section{RESÚMENES}

En la novela por entregas, el dinero asoma constantemente; sirve para comprar voluntades, para enderezar la vida de alguien desfavorecido por la fortuna, para cumplir sueños o venganzas, $y$, naturalmente, para reclamar un lugar de privilegio en la consideración y el respeto de los demás. Es el gran desencadenante de la peripecia en las novelas criminales, pero en la novela de aventuras -exóticas o no- también suele constituir la recompensa final o el elemento maravilloso, acaso en forma de tesoro. El dinero -su posesión, su generación, su falta, su búsqueda- es la clave de la organización social; en la presentación de los diversos personajes, secundarios o protagonistas, que pueblan los folletines hay una continua valoración implícita -a veces explícita- en función de la clase social a la que pertenecen; los mismos personajes parecen asumir con naturalidad la superioridad o la inferioridad del otro en función de la procedencia o el estatus. Casi cualquier acción implica un gasto, de manera que la riqueza equivale al poder. Todo tiene un precio, y a la vez hay una dimensión ética del dinero, que puede proceder del esfuerzo honrado o bien tener orígenes ilegítimos y censurables. 
ÍNDICE

Mots-clés: feuilleton, XIXe siècle, roman populaire, argent, personnage

\section{AUTOR}

JUAN FRAU

Universidad de Sevilla

jfrau@us.es 